\title{
Drug therapy of epileptic seizures among adult epileptic outpatients of University of Gondar Referral and Teaching Hospital, Gondar, North West Ethiopia
}

\author{
This article was published in the following Dove Press journal: \\ Neuropsychiatric Disease and Treatment \\ 16 December 2016 \\ Number of times this article has been viewed
}

\author{
Eshetie Melese Birru' \\ Miftah Shafi ${ }^{2}$ \\ Mestayet Geta' \\ 'Department of Pharmacology, \\ College of Medicine and Health \\ Sciences, University of Gondar, \\ Gondar, Ethiopia; ${ }^{2}$ Department of \\ Pharmacy, Health Science College, \\ Mizan-Tepi University, Mizan Aman, \\ Ethiopia
}

Correspondence: Eshetie Melese Birru Department of Pharmacology, College of Medicine and Health Sciences, University of Gondar, Chechela street, Lideta Subcity kebele 16, Gondar, Ethiopia Tel +25I 9I02I 8939

Email meshetie2I@gmail.com
Objective: The aim of this study was to assess the practice of pharmacotherapy of epilepsy and its treatment outcomes in adult epileptic outpatients at the University of Gondar Referral and Teaching Hospital, Gondar, North West Ethiopia.

Methods: An institution based, retrospective cross-sectional study was conducted from the medical charts of 336 adult epileptic patients at the outpatient epileptic clinic of Neurology Department of University of Gondar Teaching Hospital from May 2014 to April 2015. Reviewing follow-up information from the medical charts was used to evaluate antiepileptic drug (AED) prescribing patterns and treatment outcome. Data were collected by using data collection format and analyzed using SPSS software version 16.

Results: The most common type of seizure diagnosed was generalized tonic-clonic seizure ( $\mathrm{n}=245,72.91 \%$ ). Monotherapy with an AED accounted for $80.35 \%$ of the cases, whereas dual therapy and polytherapy with three AED combinations accounted for $16.37 \%$ and $3.28 \%$, respectively. The most frequently prescribed AED was phenobarbitone $(62.47 \%)$ followed by carbamazepine (17.91\%). From the total epileptic cases, 277 (82.4\%) had well-controlled seizure status in the last three consecutive months.

Conclusion: Most of the patients were maintained by monotherapy, and largely this was by the older antiepileptic drug, phenobarbitone. Considering the development of pharmacotherapy of epilepsy and other patient related factors, the standard treatment guideline for Ethiopia needs to be revised periodically.

Keywords: antiepileptics, epilepsy, treatment outcomes, prescription patterns

\section{Introduction}

Epilepsy is a serious and chronic neurologic disorder characterized by recurrent seizures that affects approximately 50 million people worldwide, of which $>80 \%$ reside in developing regions. ${ }^{1-3}$ Its overall annual incidence ranges from 50-70 cases per 100,000 in industrialized countries and up to 190 per 100,000 in developing countries. ${ }^{3}$ Like other sub-Saharan countries, Ethiopia is affected by epilepsy with the annual incidence of 64 per 100,000 inhabitants. ${ }^{4}$

About $80 \%-90 \%$ of epileptic patients of the developing countries have difficulties in accessing appropriate treatment. In addition to diagnostic difficulties, these people face different challenges of antiepileptic therapy, like inefficient and unevenly distributed health-care systems, cost of treatment, cultural attitude, economic problems, and qualitative and quantitative inadequacy of antiepileptic drugs. ${ }^{3,5-7}$ Even if a huge effort has 
been made for the development of new anti-epileptic drugs (AEDs) and improved formulations of older drugs, the AEDs we have today have limitations in their efficacy, safety, and convenience. All these are major reasons for exacerbation of social isolation, dependent behavior, low marriage rates, unemployment, psychological issues, and reduced quality of life of epileptic patients. ${ }^{3}$

The ultimate goal of treating epilepsy is maintaining seizure-free state in the absence of treatment related untoward effects and then improving the patients' quality of life. ${ }^{8}$ This necessitates the maintenance of the happy balance of efficacy and side effects by indicating appropriate AEDs considering both patient and product-related factors. If a decision is made to initiate AED therapy, it is better to start with monotherapy, and $>60 \%$ of all patients can be treated with one drug and considered well controlled, even if they may not become necessarily seizure free. But, if this is not found satisfactory, it is possible to combine AEDs having different mechanisms of action. ${ }^{9,10}$

Though different studies have been conducted in different parts of the world including Africa, there is not sufficient data on the utilization practice of antiepileptic medications and outcomes of antiepileptic therapy in Ethiopia. Accordingly, to demonstrate the existing management options of epilepsy including the outcomes and then for the improvement of quality of services, studies on the current epilepsy treatment practice have paramount importance in identifying problem areas for intervention. Thus, this study was designed to assess AED utilization pattern and treatment outcomes among epileptic patients visiting the epileptic clinic of University of Gondar Referral and Teaching Hospital.

\section{Methods}

\section{Study design}

Institution based, retrospective cross-sectional assessment of drug indication and treatment outcomes was conducted on epileptic patients' medical records of University of Gondar Referral and Teaching Hospital.

\section{Study population and inclusion criteria}

Subjects included in this study were all adult epileptic patients aged $\geq 15$ years (irrespective of gender, comorbidities) and who were on antiepileptic drug therapy follow-up in the outpatient epileptic clinic of University of Gondar Referral and Teaching Hospital from May 2014 to April 2015. Unreadable patient charts and patients who had $<6$ months follow-up duration at the time of data collection, were excluded.

\section{Sample size determination and sampling procedure}

During the study period, the total number of adult outpatient epileptic cases on follow-up was 1,500, and accordingly the assumptions made for the sample size calculation were: a $95 \%$ confidence interval (two sided), a proportion of $50 \%$, and a $5 \%$ margin of error. Ten percent (10\%) was added for possible contingencies. This gave us a sample size of 336 to be analyzed in this study. Finally, four intervals between charts were taken as a sample tracking technique. If there was a medical chart which was incomplete, the next medical chart with better information was considered.

\section{Data collection and analysis}

After all preliminary preparations for data collection were completed, the data collection format was prepared to obtain all the intended data from the medical charts. The data from the patients' medical charts were collected by trained graduating class pharmacy students in May 2015, using data collection formats. The appropriateness of AED indication was evaluated against the criteria prepared by a standard treatment guideline of Ethiopia for referral hospitals. For the evaluation of treatment outcomes, seizure status of the patients, only in the 3 month period preceding the last visit, was considered. Operationally, seizure status is said to be well controlled if there were no seizure attacks, and not well controlled if there was one or more seizure attacks in the 3 month period preceding the last visit.

The collected data were checked for completeness, accuracy, and consistency at every step during and after data collection. The data were entered and analyzed using SPSS version 16 statistical package. Frequencies, proportions, and summary statistics were used to describe the study population in relation to relevant variables. The possible drug interaction of the prescribed medications was determined by using Medscape drug interaction checker software. ${ }^{11}$

\section{Ethical consideration}

For ethical clearance, the study protocol was presented to, and approved by, the ethical review committee of the University of Gondar. In addition, since it was a retrospective design, informed consent from the participants was not required, although written permission for conducting the research was obtained from the Neurology Clinic, University of Gondar Referral and Teaching Hospital. Each patient's information was recorded in codes and kept confidential. 
Table I Age of patients at time of diagnosis of epileptic seizures in University of Gondar Referral and Teaching Hospital from May 2014 to April 2015

\begin{tabular}{llll}
\hline $\begin{array}{l}\text { Age at time } \\
\text { of diagnosis } \\
\text { (years) }\end{array}$ & $\begin{array}{l}\text { Male, } \\
\text { frequency (\%) }\end{array}$ & $\begin{array}{l}\text { Female, } \\
\text { frequency (\%) }\end{array}$ & $\begin{array}{l}\text { Total, } \\
\text { frequency (\%) }\end{array}$ \\
\hline$<I$ & $2(0.60)$ & 0 & $2(0.60)$ \\
$I-I 5$ & $45(13.4)$ & $30(8.93)$ & $75(22.3)$ \\
$16-29$ & $104(31)$ & $88(26.21)$ & $192(57.21)$ \\
$30-45$ & $27(8.03)$ & $19(5.7)$ & $46(13.73)$ \\
$46-60$ & $12(3.36)$ & $6(1.79)$ & $18(5.15)$ \\
$>60$ & $3(0.89)$ & 0 & $3(0.89)$ \\
Total & $193(57.4)$ & $143(42.6)$ & $336(100)$ \\
\hline
\end{tabular}

\section{Results}

\section{Socio-demographic characteristics}

A total of 336 patient medical records were included in this retrospective study. The demographic data revealed that the number of male and female patients was 193 (57.44\%) and 143 (42.56\%), respectively. Regarding age at the time of diagnosis, majority of the epileptic out patients were in the age range of 15-29 and 30-45 years which accounts for 226 $(67.26 \%)$ and $84(25.00 \%)$ patients, respectively. The remaining subjects were in the age range of $46-60$ and $>60$ years; $19(5.65 \%)$ and seven $(2.08 \%)$, respectively. The distribution of epilepsy in association to age is shown in Table 1.

\section{Classification of epileptic seizures}

Generalized tonic-clonic seizure (GTCS) accounted for about 245 (72.91\%), followed by $85(25.29 \%)$ unidentified and/or not recorded (Figure 1).

\section{Pharmacoepidemiologic data AED prescribing pattern}

A total of 413 AEDs were prescribed over the study period, corresponding to an average of 1.23 AED per patient. As is shown in Table 2, in this study, $270(80.35 \%)$ cases were treated with monotherapy of AEDs and 55 (16.37\%) needed dual therapy. Polytherapy was used only in eleven (3.28\%)

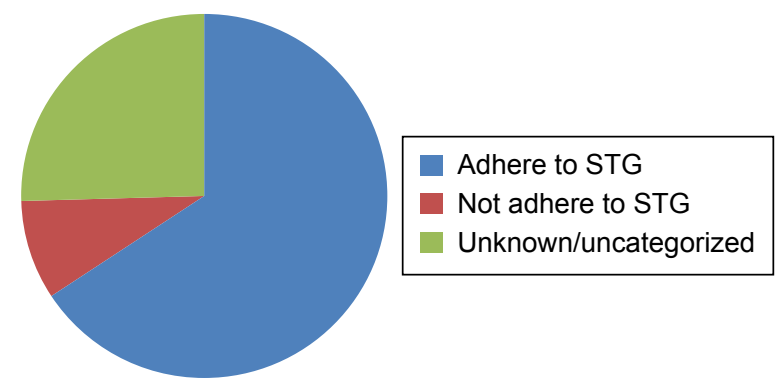

Figure I Distribution of type of seizures in epileptic patients at the University of Gondar Referral and Teaching Hospital from May 2014 to April 2015.

Abbreviation: STG, standard treatment guideline. patients. The most common drug used in monotherapy was phenobarbitone; 205 (75.93\%).

Regarding the number of AEDs prescribed, from a total of 413 prescribed AED drugs, phenobarbitone accounted for about $258(62.47 \%)$ with a dose range of 30-200 mg/day, followed by carbamazepine with a dose range of 100-400 mg/day, 74 (17.91\%); phenytoin, 61 (14.77\%); and valproic acid, 20 (4.84\%). The type of epilepsy and the antiepileptic drugs which were prescribed in the study are presented in Table 3.

\section{Reported adverse effects of AEDs}

Fifty-seven (17.6\%) patients reported that they had experienced adverse effects related to their AED therapy. Hypersomnia was the commonest adverse effect recorded (eleven [9.3\%]). The remaining adverse effects are presented in Table 4.

\section{Treatment outcome}

From 336 patients studied, 14 (4.17\%) patients were hospitalized during the 1-year follow-up period, among whom three were hospitalized due to status epilepticus and eleven were hospitalized due to other reasons like infection, depression, and surgery. The reason for hospitalizations due to status epilepticus was discontinuation of AEDs.

Considering the current status of seizure, from total subjects, 59 (17.56\%) patients had not well-controlled seizure status, and the remaining 277 (82.44\%) had well controlled seizure status in the last 3 month follow-up duration (Table 5).

\section{Drug-drug interactions}

According to Medscape, the possible drug interaction checker, from the total of 94 (27.96\%) polyprescription $(\geq 2)$ epileptic patients, 24 (25.53\%) were free of any drug interaction and $70(74.46 \%)$ of them had possible interaction, from which $44(62.86 \%)$ were significant and 26 (37.14\%) were minor interactions. From all the epileptic cases, the most commonly co-administered non-antiepileptic drug was amitriptyline, eleven (3.27\%), followed by haloperidol, seven $(2.08 \%)$, and fluoxetine, six (1.79\%) (Table 6).

\section{Adherence of AEDs prescribing to standard treatment guideline}

From 336 patients, 30 (8.9\%) of the indications for prescription of AEDs were inappropriate while 221 (65.77\%) were correctly indicated according to Ethiopia's standard treatment guideline. Also, in 85 (25.29\%) of the indications it was found difficult to know whether they were correct or incorrect 
Table 2 Type of therapy and antiepileptic drugs prescribed for epileptic patients in University of Gondar Referral and Teaching Hospital from May 2014 to April 2015

\begin{tabular}{|c|c|c|c|}
\hline Therapy type & $\mathbf{N}(\%)$ & AED & $\mathbf{N}(\%)$ \\
\hline \multirow[t]{4}{*}{ Single AED } & 270 & Phenobarbitone & $205(6 I .0 I)$ \\
\hline & & Carbamazepine & $4 \mathrm{I}(12.20)$ \\
\hline & & Phenytoin & $21(6.25)$ \\
\hline & & Valproic acid & $3(0.89)$ \\
\hline \multirow[t]{4}{*}{ Two AEDs } & 55 & Phenytoin + phenobarbitone & $26(7.74)$ \\
\hline & & Carbamazepine + phenobarbitone & $22(6.55)$ \\
\hline & & Phenobarbitone + valproic acid & $4(1.19)$ \\
\hline & & Valproic acid + phenytoin & $3(0.89)$ \\
\hline \multirow[t]{2}{*}{ Three AEDs } & 11 & Carbamazepine + valproic acid + phenytoin & $10(2.98)$ \\
\hline & & Phenytoin + phenobarbitone + carbamazepine & $\mathrm{I}(0.30)$ \\
\hline
\end{tabular}

Abbreviation: AED, antiepileptic drug.

indications since the type of epilepsy was not identified and written on the patient's medical charts (Figure 2).

\section{Discussion}

In this study, the demographic data indicated that among total patients, $57.44 \%$ were males and $67.26 \%$ patients were in the age range of 15-29 years, but trends seen in other studies show that most patients are either middle aged ${ }^{12}$ or elderly. ${ }^{13}$

Generalized tonic-clonic (72.91\%) seizures were the most common type of epileptic seizures encountered. This result is close to the study done in India $(82.0 \%)^{14}$ and different from a report from Pakistan (23.5\%). ${ }^{15}$ But, the major limitation in this report is the presence of epileptic patients' (25.29\%) medical charts without identified/recoded seizure type. This may be due to inefficient diagnostic approach and/or poor practice of health-care providers to properly record and document patients' profiles.

The proper use of drugs requires that patients receive medications appropriate to their clinical needs, in doses that meet their own individual requirements, for an adequate period of time, and at the lowest cost to them. ${ }^{16}$ Due to complexity of the pharmacotherapy of epilepsy and sociocultural attitudes toward it, assessing the prescribing practices on
AEDs is important to maintain the happy balance of efficacy and safety, and then to improve the patients' quality of life. Accordingly, this study revealed that $30(8.93 \%)$ of the indications for prescription of AEDs were inappropriate while $221(65.77 \%)$ were correctly indicated in reference to Ethiopia's standard treatment guideline. But, 85 (25.29\%) of the indications were found to be difficult to determine as to whether they were correct or incorrect indications since the type of epilepsy was not recorded on the patients' charts. The national standard treatment guideline of Ethiopia recommends valproate and carbamazepine/phenytoin as a first-line agent for both generalized and partial seizures, respectively. Similarly, according to this guideline for atonic, myoclonic, and absence seizures, valproate is the first-line agent. The alternative antiepileptic drugs listed in the guideline are phenobarbitone, clonazepam, and ethosuximide, without having additional alternatives such as the newer antiepileptic agents. ${ }^{17}$

From all the epileptic cases in this study, the majority of them were maintained on monotherapy $(80.35 \%)$, which is usually recommended as long as the epilepsy is controlled and the drug is tolerable. ${ }^{18-20}$ But this magnitude is quite different from the finding of a study conducted in India $(18.93 \%){ }^{12}$

Table 3 Types of seizure and drugs prescribed for epileptic patients in University of Gondar Referral and Teaching Hospital from May 2014 to April 2015

\begin{tabular}{|c|c|c|c|c|c|c|}
\hline \multirow[t]{2}{*}{$\overline{\text { Antiepileptic drugs }}$} & \multicolumn{6}{|c|}{ Seizure type (number of drugs) } \\
\hline & GTCs & $\begin{array}{l}\text { Status } \\
\text { epilepticus* }\end{array}$ & $\begin{array}{l}\text { Unidentified and/or } \\
\text { not recorded }\end{array}$ & Myoclonic & $\begin{array}{l}\text { Complex } \\
\text { partial }\end{array}$ & Total \\
\hline Phenobarbital & 188 & I & 66 & I & 2 & 258 \\
\hline Phenytoin & 49 & I & 10 & 0 & 1 & 61 \\
\hline Carbamazepine & 50 & - & 24 & 0 & 0 & 74 \\
\hline Valproic acid & 14 & 3 & 0 & 0 & 3 & 20 \\
\hline
\end{tabular}

Note: *Diazepam was given to some of the patients as an initial/dual therapy.

Abbreviation: GTC, generalized tonic-clonic seizure. 
Table 4 The adverse effects experienced by epileptic patients in University of Gondar Referral and Teaching Hospital from May 2014 to April 2015

\begin{tabular}{lll}
\hline $\begin{array}{l}\text { Adverse effects } \\
\text { reported }\end{array}$ & $\begin{array}{l}\text { Prescribed } \\
\text { AED(s) }\end{array}$ & $\begin{array}{l}\text { Frequency, } \\
\text { N (\%) }\end{array}$ \\
\hline Headache & $\begin{array}{l}\text { Phenobarbitone and } \\
\text { carbamazepine }\end{array}$ & $8(14.04)$ \\
Constipation & Carbamazepine & $4(7.02)$ \\
Vomiting & Phenobarbitone & $2(3.51)$ \\
Gingival hypertrophy & Phenytoin & $4(7.02)$ \\
Psychomotor impairment & Phenobarbitone & $2(3.51)$ \\
Gastric stress & Carbamazepine & $3(5.26)$ \\
Hypersomnia & Phenobarbitone & II (19.30) \\
Skin rash & Phenobarbitone & I (1.75) \\
Joint pain & Phenobarbitone & $4(7.02)$ \\
Dizziness & Phenobarbitone & $7(12.28)$ \\
Hepatotoxicity & Carbamazepine & $5(8.77)$ \\
Shortness of breath & Phenobarbitone & $3(5.26)$ \\
Sedation & Phenobarbitone & $3(5.26)$ \\
Total & & $57(100)$ \\
\hline
\end{tabular}

Abbreviation: AEDs, antiepileptic drugs.

The best AED therapy is dependent on optimal seizure control and absence of unacceptable side effects. ${ }^{18,19}$ But at present, carbamazepine and valproate are evidence-based treatment recommendations for partial and generalized onset seizures, respectively, and phenobarbitone is usually considered as second-/third-line option ${ }^{20-23}$ due to less tolerable adverse drug reactions like sedation and cognitive impairments. ${ }^{19}$ As a result, most of the epileptic patients of our study area are prone to nonadherence to the regimen and to refractory type of epilepsy.

In this study, phenobarbitone 205 (75.95\%) was the most frequently prescribed monotherapy, followed by carbamazepine 41 (15.18\%), even if it was not the first-line agent for any type of epileptic case as per the standard treatment guideline. Similarly, phenytoin with phenobarbitone was the most frequently indicated dual therapy in this study $26(47.27 \%)$. Even though the combination of phenytoin and

Table 5 Seizure attacks in the last 3 months among epileptic patients in University of Gondar Referral and Teaching Hospital from May 2014 to April 2015

\begin{tabular}{llll}
\hline Type of seizure & \multicolumn{3}{l}{ Seizure attacks in the last 3 months } \\
\cline { 2 - 4 } & Yes $(\mathbf{N}, \%)$ & No $(\mathbf{N}, \%)$ & Total \\
\hline GTCs & $4 \mathrm{I}(16.73)$ & $204(83.27)$ & 245 \\
Status epilepticus & $0(0)$ & $3(100)$ & 3 \\
Myoclonic & $0(0)$ & $1(100)$ & $\mathrm{I}$ \\
Complex partial & $0(0)$ & $2(100)$ & 2 \\
Unknown & $18(21.18)$ & $67(78.82)$ & 85 \\
Total & $59(17.56)$ & $277(82.44)$ & 336 \\
\hline
\end{tabular}

Abbreviation: GTC, generalized tonic-clonic seizure.
Table 6 Drug interaction with co-administered medicines among epileptic patients in University of Gondar Referral and Teaching Hospital from May 20I4 to April 2015

\begin{tabular}{llll}
\hline Co-administered & AEDs & \multicolumn{2}{l}{ Level of interaction* } \\
\cline { 2 - 4 } medicines & & Significant & Minor \\
\hline Paracetamol & Carbamazepine & - & 1 \\
& Phenobarbitone & - & 3 \\
Omeprazole & Phenytoin & $\mathrm{I}$ & - \\
& Phenytoin & $\mathrm{I}$ & - \\
& Phenobarbitone & & - \\
Haloperidol & Carbamazepine & $\mathrm{I}$ & - \\
& Phenobarbitone & 2 & - \\
Amitriptyline & Phenobarbitone & 7 & - \\
Risperidone & Phenytoin & 3 & - \\
& Carbamazepine & I & \\
& Carbamazepine + & $\mathrm{I}$ & - \\
Fluoxetine & valproic acid + & & \\
& Phenytoin & & \\
& Phenobarbitone + & $\mathrm{I}$ & \\
& valproic acid & &
\end{tabular}

Notes: *Level of interaction was checked by using Medscape. - No known interaction. Abbreviation: AEDs, antiepileptic drugs.

phenobarbitone is important in maximizing seizure control, the risk of toxicity is high. The failure of AED monotherapy could be associated with multiple factors, for example, pharmacogenetic factors, misinterpretation of seizure type that leads to ineffective AED choice, and noncompliance due to adverse effects. ${ }^{24}$ Polytherapy offers no advantage over monotherapy, because it increases the potential for drugdrug interactions, may affect compliance, and is associated with a higher cost of medication requirement of therapeutic drug monitoring. ${ }^{23,24}$ Furthermore, apart from their efficacy and tolerability issue, the older AEDs have complex pharmacokinetic and pharmaceutical properties that may lead to serious drug interactions when they are given in combination. Currently, newer AEDs are approved and get into the market and have preferable effectiveness in some patients with different clinical conditions. Thus, when it is justifiable

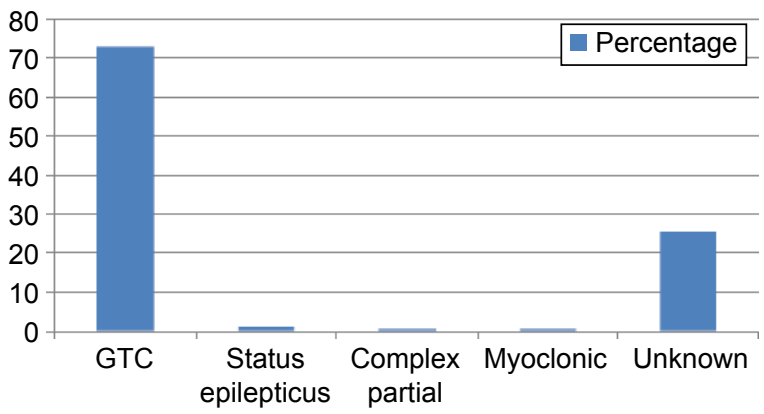

Figure 2 Adherence of AEDs prescribing to STG in University of Gondar Referral and Teaching Hospital from May 2014 to April 2015.

Abbreviations: AEDs, antiepileptic drugs; GTC, generalized tonic-clonic seizure; STG, standard treatment guideline. 
in terms of efficacy, safety, and even cost it might be rational to prescribe newer classes in place of the older AEDs. ${ }^{24}$

Among the 57 patients complaining of adverse drug effects, hypersomnia was the most common adverse effect reported by eleven (19.29\%) patients, as retrieved from the patients' medical records, and this finding differs from a study done in Bishoftu, Ethiopia, which reported 6\%. ${ }^{25}$ Most of the adverse effects reported here in this study are associated with phenobarbitone which is in line with other reports, confirming adverse effects limit its clinical use. ${ }^{19}$ In this study, all the AED induced adverse effects were from patients' self-report, and thus known biochemical effects of these drugs like the metabolic syndromes of valproic acid were not addressed. ${ }^{26,27}$

Regarding antiepileptic treatment outcomes, this study showed that almost $82.45 \%$ of patients were found to be seizure free for the last 3 consecutive month follow-up period. This statistic is higher compared with a study done on seizure attacks in medically treated adult epilepsy patients in Cleveland clinic, USA where $63 \%$ of patients were completely seizure free at 6 months, and 64\% were completely seizure free at 12 months, even though the discrepancy might be due to methodological difference. ${ }^{28}$

From all the patients who were taking two or more drugs, $70(74.46 \%)$ of them had possible drug interaction; $44(62.86 \%)$ were significant and 26 (37.14\%) were minor interactions. The major mechanisms for their interaction are believed to be modulation of microsomal enzymatic expression, plasma protein binding, and overlapping peripheral and central side effects. ${ }^{24}$

This study being retrospective, suffered from lack of adequate and complete information on medical charts, and this made it difficult to do inferential statistics in adjusting and estimating the association of independent variables with antiepileptic treatment outcomes.

\section{Conclusion}

Phenobarbitone was found to be the most commonly prescribed AED, and also, most of the patients were on monotherapy. More than three-quarters of the patients were also seizure free in the last 3 month follow-up period. Health-care providers have to improve their adherence to the treatment guideline and to the recording and documentation of patients' profiles.

\section{Acknowledgments}

The authors are thankful to the data collectors Hayal Wondmu, Mahlet Molla, Michael Legesse, and Mustefa Geda. In addition, we are grateful to the Neurology Department of University of Gondar Referral and Teaching Hospital and its health-care providers.
The abstract of this paper was presented at the ISPOR 21st Annual International Meeting, Washington DC, USA, May 2016 as an abstract with interim findings. The abstract was published in Value in Health 19(3):A35 May 2016.

\section{Author contributions}

All authors were involved in the design, writing, preparation, and critical revision of the manuscript. EMB and MS conducted the statistical analysis. All authors approved the submitted version of the manuscript, and they are accountable for all aspects of the work in ensuring that questions related to the accuracy or integrity of any part of the work were appropriately investigated and resolved.

\section{Disclosure}

The authors report no conflicts of interest in this work.

\section{References}

1. Leppik IE. Contemporary diagnosis and management of the patient with epilepsy. 2nd ed. Newtown, PA: Handbooks in Health Care Company. 2011.

2. World Health Organization. Epilepsy, Fact Sheet. Geneva: Number 999; 2009.

3. Wahab A. Difficulties in treatment and management of epilepsy and challenges in new drug development. Pharmaceuticals (Basel). 2010; 3(7):2090-2110.

4. Tekle-Haimanot R, Forsgren L, Ekstendt J. Incidence of epilepsy in rural central Ethiopia. Epilepsia. 1997;38(5):541-546.

5. Scott RA, Lhatoo SD, Sander JW. The treatment of epilepsy in developing countries: where do we go from here? Bull WHO. 2001;79(4): 344-351.

6. Heaney DC, Beran RG, Halpern MT. Economics in epilepsy treatment choices: our certain fate? Epilepsia. 2002;43(4):32-38.

7. García-Morales I, Sancho Rieger J, Gil-Nagel A, Herranz Fernández JL. Antiepileptic drugs: from scientific evidence to clinical practice. Neurologist. 2007;13(6 Suppl 1):S20-S28.

8. Vickry BG, Hays RD, Rausch R, Sutherling WW, Engel J Jr, Brook RH. Quality of life of epilepsy surgery patients as compared with outpatients with hypertension, diabetes, heart disease, and/or depressive symptoms. Epilepsia. 1994;35(3):597-607.

9. Brodie MJ, French JA. Management of epilepsy in adolescents and adults. Lancet. 2000;356(9226):323-329.

10. Mattson RH. Antiepileptic drug monotherapy in adults: selection and use in new-onset epilepsy. In Levy RH, Mattson RH, Meldrum BS, editors. Antiepileptic drugs, 5th ed. Philadelphia, PA: Lippincott Williams \& Wilkins; 2002:72-95.

11. Medscape drug interaction checker. http://reference.medscape.com/ drug-interactionchecker. Accessed June 14, 2015.

12. Pal A, Prusty SK, Sahu PK, Swain T. Drug utilization pattern of antiepileptic drugs: a pharmacoepidemiologic and pharmacovigilance study in a tertiary teaching hospital in Iindia. Asian J Pharm Clin Res. 2011; 4(1):96-99.

13. Moran NF, Poole k, Bell G, et al. Epilepsy in the United Kingdom: seizure frequency and severity, anti-epileptic drug utilization and impact on life in 1,652 people with epilepsy. Seizure. 2004;13(6):425-433.

14. Sebastian J, Adepu R, Keshava BS, Harsha S. Assessment of antiepileptic drugs usage in a South Indian tertiary care teaching hospital. Neurology Asia. 2013;18(2):159-165.

15. Mazhar F, Shamim S, Malhi SM. Drug utilization evaluation of antiepileptics in three selected multidisciplinary teaching hospitals of Pakistan. Int J Pharm Pharm Sci. 2014;6(5):59-66. 
16. WHO: The rational use of drugs. Report of a Conference of Experts, Nairobi, 25-29 November 1985. Geneva: World Health Organization; 1987.

17. Food, Medicine and Healthcare Administration and Control Authority of Ethiopia Ethiopia. Standard Treatment Guidelines for General Hospital. 3rd ed. 2014.

18. Glauser T, Ben-Menachem E, Bourgeois B, et al. ILAE treatment guidelines: evidence-based analysis of antiepileptic drug efficacy and effectiveness as initial monotherapy for epileptic seizures and syndromes. Epilepsia. 2006;47(7):1094-1120.

19. Brodie MJ, Dichter MA. Antiepileptic drugs. N Engl J Med. 1996;334: 168-175.

20. Sander JW. The use of antiepileptic drugs - principles and practice. Epilepsia. 2004;45(Suppl 6):28-34.

21. Lim SH, Tan EK, Chen C. Pattern of anti-epileptic drug usage in a tertiary referral hospital in Singapore. Neurol J South East Asia. 1997;2: 77-85.

22. Gurshaw M, Agalu A, Chanie T. Anti-epileptic drug utilization and treatment outcome among epileptic patients on follow-up in a resource poor setting. JYP. 2014;6(3):47-52.
23. Smith D, Chadwick D. Management of epilepsy. J Neurol Neurosurg Psychiatry. 2001;70(2):15-21.

24. Abdul Wahab. Difficulties in treatment and management of epilepsy and challenges in new drug development. Pharmaceuticals (Basel). 2010;3(7): 2090-2110.

25. Rishe W, Seifu MF, Gelaw BK, Gunasekaran T, Gebremariam ET, Mohammed MA. Drug use evaluation of antiepileptic drugs in outpatient epilepsy clinic of bishoft general hospital, East Shoa, Ethiopia. Int Res Dev Pharm L Sci. 2015;4(3):1516-1528.

26. Verrotti A, Manco R, Agostinelli S, Coppola G, Chiarelli F. The metabolic syndrome in overweight epileptic patients treated with valproic acid. Epilepsia. 2010;51(2):268-273.

27. Arya R, Gillespie CW, Cnaan A, et al; Childhood Absence Epilepsy Study Group. Obesity and overweight as CAE comorbidities and differential drug response modifiers. Neurology. 2016;86(17):1613-1621.

28. Cleveland Clinic; Epilepsy Centre. Outcomes report; 2011. Available from: http://www.my.clevelandclinic.org/neurological_institute/epilepsy/ treatments services/treatment-outcomes.aspx. Accessed May 15, 2013.
Neuropsychiatric Disease and Treatment

\section{Publish your work in this journal}

Neuropsychiatric Disease and Treatment is an international, peerreviewed journal of clinical therapeutics and pharmacology focusing on concise rapid reporting of clinical or pre-clinical studies on a range of neuropsychiatric and neurological disorders. This journal is indexed on PubMed Central, the 'PsycINFO' database and CAS,

\section{Dovepress}

and is the official journal of The International Neuropsychiatric Association (INA). The manuscript management system is completely online and includes a very quick and fair peer-review system, which is all easy to use. Visit http://www.dovepress.com/testimonials.php to read real quotes from published authors.

Submit your manuscript here: http://www.dovepress.com/neuropsychiatric-disease-and-treatment-journal 